University of Nebraska - Lincoln

DigitalCommons@University of Nebraska - Lincoln

Uniformed Services University of the Health

Sciences

U.S. Department of Defense

2011

\title{
Incidence of tricyclic antidepressant-like complications after cyclobenzaprine overdose
}

\author{
Vikhyat S. Bebarta \\ Wilford Hall Medical Center, vikbebarta@yahoo.com \\ Joseph Maddry \\ Wilford Hall Medical Center, joseph.maddry@gmail.com \\ Douglas J. Borys \\ Central Texas Poison Center, dborys@swmail.sw.org \\ David L. Morgan \\ Scott and White Hospital, dlmorgan@swmail.sw.org
}

Follow this and additional works at: https://digitalcommons.unl.edu/usuhs

Part of the Medicine and Health Sciences Commons

Bebarta, Vikhyat S.; Maddry, Joseph; Borys, Douglas J.; and Morgan, David L., "Incidence of tricyclic antidepressant-like complications after cyclobenzaprine overdose" (2011). Uniformed Services University of the Health Sciences. 28.

https://digitalcommons.unl.edu/usuhs/28

This Article is brought to you for free and open access by the U.S. Department of Defense at DigitalCommons@University of Nebraska - Lincoln. It has been accepted for inclusion in Uniformed Services University of the Health Sciences by an authorized administrator of DigitalCommons@University of Nebraska Lincoln. 


\title{
Original Contribution
}

\section{Incidence of tricyclic antidepressant-like complications

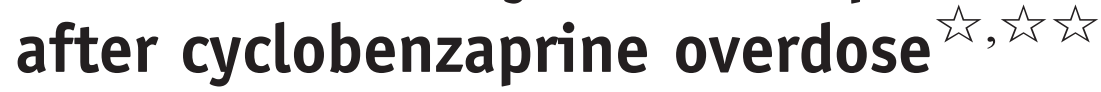

\author{
Vikhyat S. Bebarta $M D^{a, *}$, Joseph Maddry $M^{b}{ }^{b}$, \\ Douglas J. Borys PharmD ${ }^{c}$, David L. Morgan MD ${ }^{d}$
}

\author{
${ }^{a}$ Department of Emergency Medicine, Wilford Hall Medical Center, San Antonio, TX 78261, USA \\ ${ }^{\mathrm{b}}$ Emergency Medicine, San Antonio Uniformed Services Health Education Consortium, Wilford Hall Medical Center, \\ San Antonio, TX 78261, USA \\ ${ }^{\mathrm{c}}$ Central Texas Poison Center, Temple, TX, USA \\ ${ }^{\mathrm{d} E m e r g e n c y ~ M e d i c i n e, ~ T e x a s ~ A ~ \& ~ M ~ U n i v e r s i t y ~ H e a l t h ~ S c i e n c e ~ C e n t e r ~ C o l l e g e ~ o f ~ M e d i c i n e, ~ S c o t t ~ a n d ~ W h i t e ~ H o s p i t a l, ~}$ \\ Temple, TX, USA
}

Received 7 December 2009; revised 5 January 2010; accepted 7 January 2010

\begin{abstract}
Background: The cyclobenzaprine structure is similar to amitriptyline; however, tricyclic antidepressant (TCA)-like wide complex dysrhythmia has not been reported. Our objective was to determine the incidence of TCA-like effects in cyclobenzaprine overdoses as reported to 6 poison centers for 2 years. We compared the incidence of these effects to amitriptyline overdoses collected during the same period. Methods: We performed a retrospective review of 2 years of cases as reported to the Texas Poison Center Network. We identified sole ingestions of cyclobenzaprine and of amitriptyline. Cases had a recorded clinical outcome and clinical effect. A trained reviewer used a standard data collection sheet within a secured electronic database. One investigator audited a random sample of charts.

Results: We identified 3974 cases of cyclobenzaprine calls. Of these, we collected 209 cases of acute overdoses without coingestions. There were no deaths. No cases of cyclobenzaprine ingestions were reported to have died or have a wide QRS or ventricular dysrhythmia. Seizures were reported in 2 cases; however, both were unrelated to cyclobenzaprine. Hypotension was reported in $1.4 \%(3 / 209)$ of cases, and a vasopressor was used in one case $(0.5 \%)$. Patients with an amitriptyline overdose were more likely to have seizure, coma, tachycardia, a wide QRS or ventricular dysrhythmia, and have received sodium bicarbonate or be intubated.

Conclusions: Cyclobenzaprine overdoses were not reported to cause widened QRS, ventricular dysrhythmias, or seizures, and hypotension was rarely reported. Tricyclic antidepressant-related effects occurred more often in our comparison group of amitriptyline overdoses.
\end{abstract}

(C) 2011 Published by Elsevier Inc.

\footnotetext{
is Oral presentation at the Mediterranean Emergency Medicine Conference-March 2007.

is the authors have no financial support or financial interest in the subject matter discussed. The views expressed in this article are those of the authors and do not reflect the official policy or position of the Department of the United States (U.S.) Air Force, Department of Defense, or the US government.

* Corresponding author. Tel.: +1 2102923908 (work); fax: +1 7024427921.

E-mail addresses: vikbebarta@yahoo.com (V.S. Bebarta),joseph.maddry@gmail.com (J. Maddry), dborys@swmail.sw.org (D.J. Borys), dlmorgan@swmail.sw.org (D.L. Morgan).
} 


\section{Introduction}

Cyclobenzaprine is tricyclic amine, structurally similar to amitriptyline, which is used for muscle pain and spasm [1] (Fig. 1). It has antihistaminic, anticholinergic, and sedative properties. It is a weak inhibitor of norepinephrine and serotonin reuptake. It was created as antidepressant but had more adverse effects and less antidepressant effects than other tricyclic antidepressants (TCAs) [2,3]. It is the most common prescribed muscle relaxant and accounts for $18 \%$ of all prescriptions written for chronic back pain [4]. However, effectiveness for chronic pain is inconclusive [5,6]. It accounts for 8760 overdoses a year, $30 \%$ of all overdoses from muscle relaxants [7].

Because of its similar structure to amitriptyline and other tricyclics (a difference of one double bond), previous publications and authors suggest wide QRS and ventricular dysrhythmias are possible adverse effects of cyclobenzaprine overdose $[8,9]$. Although in one series of unintentional and intentional ingestions, no wide complex dysrhythmia occurred, a recent abstract showed a slightly widened QRS hours after ingestion $[10,11]$.

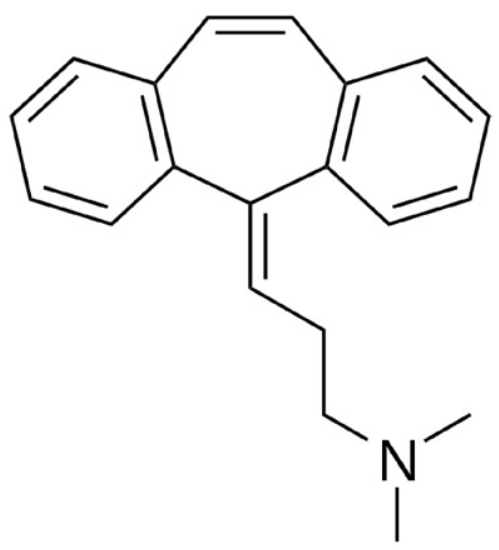

Cyclobenzaprine

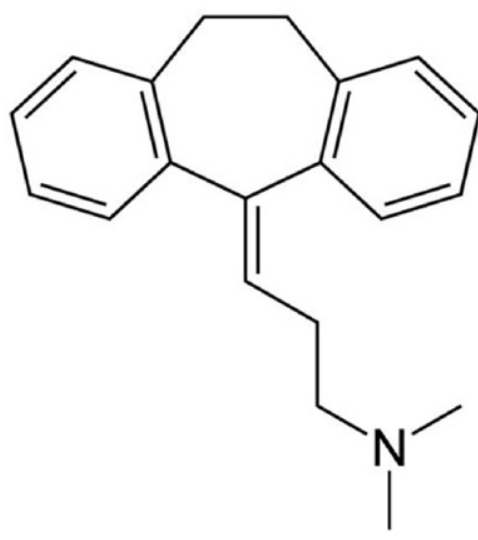

Amitriptyline

Fig. 1 Structures of cyclobenzaprine and amitriptyline.
We sought to determine the incidence of ventricular dysrhythmias and a widened QRS in a large series of cyclobenzaprine overdoses as reported to 6 poison centers for 2 years. We also sought to determine the incidence of other serious TCA-like effects. Finally, we aimed to compare the serious adverse effects of cyclobenzaprine to amitriptyline over the same period.

\section{Methods}

\subsection{Study design}

\subsubsection{Setting and selection of participants}

We performed a retrospective cohort study approved by our institutional review board. We searched 2 years (20052006) of the electronic database Toxicall of the Texas Poison Center Network. This database includes all calls made to a poison center within Texas. We used the POISONDEX product identification codes for cyclobenzaprine and amitriptyline to identify all cases. Our network is made of 6 poison centers, and calls are received and documented by trained poison information specialists (SPIs). They enter clinical notes and document standardized codes for common symptoms, signs, treatments, procedures, and disposition. They also enter free text clinical notes. We included all acute intentional ingestions of cyclobenzaprine without coingestions. Cases had a recorded clinical outcome and clinical effect. Patients 12 years and older were included. We used the same criteria to search for all amitriptyline ingestions.

Symptoms, signs, treatments, procedures, and outcomes were extracted from the database through chart review of the clinical notes and coded diagnoses and treatments. We did not use the outcomes of "No effect," "Minor," "Moderate," "Major," and "Death" as defined according to the American Association of Poison Centers outcome criteria [7]. Instead, we recorded the effects and outcomes as documented by the specialist in poison information or toxicologist.

\subsubsection{Data collection and processing}

We saved the charts electronically and then printed and reviewed them individually. One trained abstractor (JM) reviewed the charts and entered the data into a secure spreadsheet. The abstractor reviewed the clinical notes for symptoms, signs, and treatments not coded by the SPI. One of the investigators (VB) trained the abstractor. The abstractor trained on 50 charts not included in the study cohort. He was given feedback on data abstraction and corrected mistakes. The standard data collection tool was devised before this run-in period and revised before the chart review began.

We used the American Association of Poison Centers definitions for dysrhythmia (ventricular tachycardia, ventricular fibrillation, or torsades de pointe), hypotension (systolic blood pressure, $<90 \mathrm{~mm} \mathrm{Hg}$ ), tachycardia (pulse rate, $>100$ $\mathrm{mm} \mathrm{Hg}$ ), and hypertension (diastolic blood pressure, $>90$ 
$\mathrm{mm} \mathrm{Hg}$ ) [12]. We defined a wide QRS as more than 100 milliseconds [13]. For a discrepant case, 2 authors reviewed the case and determined if the outcome was present to ensure the broadest capture of cases. Other data collection variables included demographics (age, sex), exposure reason, symptoms, treatments, procedures, and disposition. Both coded and free text answers were included. Definitions and outcomes were defined before abstraction. Once the chart review began, periodic meetings were completed to resolve discrepancies. One investigator (VB) audited a random sample of $10 \%$ the charts to assess for accuracy. He reviewed the outcomes for wide QRS, ventricular dysrhythmia, seizure, tachycardia, and hypotension. The auditor was blinded to the disposition and ingestant for each case, and he was blinded to the initial abstractor's data.

\subsubsection{Outcomes measured}

Our primary outcome was ventricular dysrhythmia or widened QRS on the electrocardiogram. This outcome was included if noted in the coded "clinical effects" categories or clinical notes section of the database collection form. Our secondary outcomes were hypotension, seizure, tachycardia, use of sodium bicarbonate for wide QRS, intubation, intensive care unit (ICU) admission, death, or use of defibrillation, antidysrhythmics, vasopressor agents, antiepileptic medications, or sodium bicarbonate for wide QRS. Clinical effects due to the ingestant were included. Discrepancies were resolved by consensus of 2 authors. We compared the signs, treatments, procedures, and outcomes with the group of amitriptyline ingestions. We chose amitriptyline because of its effects as a potent tricyclic and its similarity in structure to cyclobenzaprine [1].

\subsubsection{Primary data analysis}

We entered all data into a password-protected electronic spreadsheet (Microsoft Excel, 2007; Microsoft

Table 1 Demographics of patients with acute intentional cyclobenzaprine and amitriptyline ingestions compared with $\chi^{2}$

\begin{tabular}{llll}
\hline Category & $\begin{array}{l}\text { Cyclobenzaprine }(\%), \\
(\mathrm{n}=209)\end{array}$ & $\begin{array}{l}\text { Amitriptyline }(\%), ~ \\
(\mathrm{n}=262)\end{array}$ \\
\hline $\begin{array}{l}\text { Male } \\
\text { Mean }\end{array}$ & $63(30)$ & $94(36)$ & .2 \\
$\quad$ age (y) & 30.4 & 35.5 & - \\
$\begin{array}{c}\text { Decontamination } \\
\text { Gastric } \\
\text { lavage }\end{array}$ & $14(0.07)$ & $18(0.18)$ & 1.0 \\
$\begin{array}{c}\text { Activated } \\
\text { charcoal }\end{array}$ & $92(44)$ & $141(54)$ & $.041^{\text {a }}$ \\
$\begin{array}{c}\text { Disposition } \\
\text { Admitted }\end{array}$ & $87(42)$ & & \\
Admitted & $40(19)$ & $170(65)$ & $.001^{\mathrm{a}}$ \\
to ICU & & $132(50)$ & $.001^{\mathrm{a}}$ \\
\hline
\end{tabular}

a Statistical difference.
Table 2 Comparison of clinical outcomes and treatments between cyclobenzaprine and amitriptyline acute intentional ingestions with $\chi^{2}$

\begin{tabular}{|c|c|c|c|}
\hline Category & $\begin{array}{l}\text { Cyclobenzaprine } \\
(\%),(n=209)\end{array}$ & $\begin{array}{l}\text { Amitriptyline } \\
(\%),(\mathrm{n}=262)\end{array}$ & $P$ \\
\hline \multicolumn{4}{|c|}{ Serious clinical effects } \\
\hline Seizure & $0(0)$ & $6(0.02)$ & $.036^{\mathrm{a}}$ \\
\hline Hypotension & 3 & $10(0.04)$ & .16 \\
\hline $\begin{array}{l}\text { Wide QRS or } \\
\text { ventricular } \\
\text { dysrhythmia }\end{array}$ & $0(0)$ & $30(11)$ & $.0001^{\mathrm{a}}$ \\
\hline Coma & $1(0.004)$ & $29(11)$ & $.0001^{\mathrm{a}}$ \\
\hline Death & $0(0)$ & $1(0.004)$ & .44 \\
\hline \multicolumn{4}{|c|}{ Other clinical effects } \\
\hline Hypertension & $30(14)$ & $53(20)$ & .11 \\
\hline Drowsiness & $87(42)$ & $127(48)$ & .16 \\
\hline Tachycardia & $57(27)$ & $112(43)$ & $.0005^{\mathrm{a}}$ \\
\hline \multicolumn{4}{|l|}{ Treatments } \\
\hline $\begin{array}{l}\text { Sodium } \\
\text { bicarbonate }\end{array}$ & $3(0.01)$ & $82(31)$ & $.0001^{\mathrm{a}}$ \\
\hline Vasopressor & $1(0.004)$ & $5(0.02)$ & .093 \\
\hline Intubation & $10(5)$ & $56(21)$ & $.0001^{\mathrm{a}}$ \\
\hline $\begin{array}{l}\text { Antiseizure } \\
\text { medication }\end{array}$ & $0(0)$ & $2(0.008)$ & .51 \\
\hline $\begin{array}{l}\text { Cardioversion or } \\
\text { defibrillation }\end{array}$ & $0(0)$ & $1(0.004)$ & .44 \\
\hline
\end{tabular}

Corporation, Redmond, Wash). We performed descriptive statistics. We compared with groups with $\chi^{2}$ or Fisher exact (when indicated) for selected clinical features, treatments, and outcomes between cyclobenzaprine and amitriptyline.

\section{Results}

We identified 3974 cases of cyclobenzaprine calls to the 6 poison centers in 2005 and 2006. Of these, 1043 were human exposures. Of these, we collected 209 cases of cyclobenzaprine acute intentional ingestions without coingestions. Thirty percent were male $(63 / 209)$, and the mean age was 30.3 years (range, 12-63 years old) (Table 1). There were no deaths in the cyclobenzaprine group. No case of cyclobenzaprine ingestions was reported to have a wide QRS or ventricular dysrhythmia (Table 2). Two patients received sodium bicarbonate, but no explanation was given and no case had dysrhythmia, seizure, or hypotension noted. Seizures were reported in 2 cases; however, one had hyponatremia and the other had a large brain mass. In both cases, the SPI documented that the seizures were unrelated to cyclobenzaprine. Our abstractor concurred with these assessments. Drowsiness was reported in $42 \%$ of cases, and intubation was reported in $5 \%$ of cases. Hypotension was reported in $1.4 \%$ $(3 / 209)$ of cases, and a vasopressor (dopamine) was used on one of these cases $(0.5 \%)$. In the case with dopamine use, a 
urine toxicology screen was positive for barbiturates. No case of rhabdomyolysis was reported.

We compared the clinical features, treatments, procedures, and dispositions of patients with cyclobenzaprine overdose to those with amitriptyline overdose during the same period (Table 2). Patients with an amitriptyline overdose were more likely to have seizure, coma, tachycardia, a wide QRS, or ventricular dysrhythmia and have received sodium bicarbonate. They were also more likely to be admitted to the ICU and be intubated. The proportion of patients in the amitriptyline group with hypotension or vasopressor use was greater, but there was no statistical difference between groups. No patient in either group received physostigmine or antidysrhythmics. Two patients received nonbenzodiazepine antiseizure medications in the amitriptyline group and none in cyclobenzaprine group. Reversal agent use (naloxone or flumazenil) was similar in both groups.

Audit of $10 \%$ of the charts by a reviewer showed overall agreement for wide QRS or ventricular dysrhythmia with a $\kappa$ of 1.0 (95\% confidence interval [CI], 1.0-1.0). Agreement for were seizures $(\kappa, 1.0)$, tachycardia $(\kappa, 0.77 ; 95 \% \mathrm{CI}$, $0.34-1.2)$, and hypotension ( $\kappa, 0.83 ; 95 \% \mathrm{CI}, 0.5-1.2)$ were also high. There were no deaths in the sample.

\section{Discussion}

The results of our study suggests that widened QRS and ventricular dysrhythmias are rare after acute intentional cyclobenzaprine overdose based on cases reported to our 6 poison centers over 2 years. Our patients manifested anticholinergic symptoms (sedation, tachycardia, mild hypertension) but did not develop the serious complications of TCA effects such as dysrhythmia and seizure, despite its structure is similar to TCAs. Hypotension was uncommon (3 cases). In addition, significant tricyclic effects were more common in the amitriptyline group. As a surrogate marker of severity of illness of the patients in the amitriptyline group, the rates of admission, ICU admission, intubation, and use of sodium bicarbonate were higher.

Although textbooks and review articles suggest dysrhythmia and other serious TCA-like effects can occur, previous cases and a large case series do not support this $[8,9,14]$. In several cases of cyclobenzaprine overdose, seizure, dysrhythmia, and hypotension were not reported $[14,15]$. In the series by Dr Spiller [10] of undifferentiated unintentional and intentional cases of all ages reported to several poison centers, no patient developed ventricular dysrhythmia or seizure, and no patient died. These results were similar to ours. In addition, hypotension occurred in less than $2 \%$ of cases older than 10 years, and vasopressors were used in less than $1 \%$ of cases, which are also similar to our results. Although the study by Spiller is similar to ours, we only included acute intentional overdoses in subjects older than 11 years; the group assumed to have the highest risk for developing toxic effects. In addition, our methods for data abstraction were explicit and verified by audit as outlined by Gilbert et al [16]. Finally, we directly compared our risk of TCA-like effects with a parallel group of acute intentional amitriptyline overdoses during the same period and poison centers. Our data are also consistent with postmarketing data that reported seizures and dysrhythmias each in less than $0.1 \%$ of cases [17]. However, in one unpublished case, authors reported a slightly widened QRS (90 to 100 milliseconds) after ingesting an estimated $2750 \mathrm{mg}$ of cyclobenzaprine. However, this widening occurred on the second hospital day, which is not consistent with typical tricyclic effects that usually occur within the first 6 hours of ingestion [18]. The patient received sodium bicarbonate infusion, and the QRS narrowed to 86 milliseconds by hospital day 12 [11]. Death has been reported after cyclobenzaprine ingestion; however, both cases had a respiratory depressant coingestant, and the cyclobenzaprine dose ingested was calculated from postmortem levels, which are unreliable [19].

Although the mechanism for the lack of TCA-like effects is unclear, there are 2 plausible mechanisms. First, although cyclobenzaprine is structurally similar to amitriptyline (difference of one double bond), it is possibly less potent than other tricyclics [3]. In animal models, it also has some antiepileptic effects ,which is consistent with its possible antispastic effects [20]. Second, one tablet is $10 \mathrm{mg}$, thus, intentional ingestions greater than $1 \mathrm{~g}$ are difficult to achieve, and cardiotoxic and neurotoxic doses are not ingested $[10,15]$. However, several cases of 1 to $3 \mathrm{~g}$ have been reported without seizures and dysrhythmia, thus, the lack of toxicity is likely a combination of mechanisms - a lack of potency and insufficient dose. Large cyclobenzaprine overdoses can still induce severe sedation and tachycardia requiring intensive monitoring and intubation as evidenced in our study.

This study has several limitations. First, our study used data from public and health care provider calls to poison centers [21]. It is possible that patients with severe adverse effects were not reported to the poison center and managed with consultants at the hospital. In addition, the primary provider may not have reported the serious adverse effects to the poison center specialist. Second, the data are only from the poison center data, not hospital records, which would be more detailed. In addition, the follow-up on the cases is limited, although most of the severe effects would likely occur in the first 24 hours of admission. Another limitation is the moderate sample size for 2 years. It is possible that a larger sample size collected over several more years could capture patients with dysrhythmias or seizures, if they were to occur. However, our data suggest the risk of these adverse effects are less than $0.5 \%$ and is consistent with previous reports $[10,17]$. Our data were collected from Texas; results could vary in other geographic regions, although, cyclobenzaprine use is ubiquitous and our results are consistent with reports from outside Texas. Finally, the higher rates of 
intubation and ICU admission could be a secondary concern for potential adverse effects of TCA rather than a surrogate of illness severity. Nonetheless, the rates of intubated and ICU admission were lower in the cyclobenzaprine group and is consistent with the lower rates of severe tricyclic-like effects in the cyclobenzaprine group in our study.

In conclusion, widened QRS, ventricular dysrhythmias, seizures, or death was not reported in our study of acute intentional ingestions of cyclobenzaprine reported to poison centers. Hypotension rarely occurred, although the difference between cyclobenzaprine and amitriptyline was not significant. Rates of these tricyclic effects were much higher in our parallel comparison group of amitriptyline overdoses. Cyclobenzaprine overdoses should be observed for sedation and tachycardia, and cases should be managed for anticholinergic toxicity and evaluated for coingestions rather than a tricyclic-like syndrome.

\section{References}

[1] Hurlbut KM. General muscle relaxants. In: Dart RC, editor. Medical toxicology. 3rd ed. Philadelphia: Lippincott, Williams \& Wilkins; 2004. p. 594-601.

[2] Vinar O, Grof P. Proheptatriene in depression (extensive study). Act Nerv Super (Praha) 1965;7(3):290.

[3] Benesova O, Nahunek K. Correlation between the experimental data from animal studies and therapeutical effects of antidepressant drugs. Psychopharmacologia 1971;20(4):337-47.

[4] Luo X, Pietrobon R, Curtis LH, et al. Prescription of nonsteroidal antiinflammatory drugs and muscle relaxants for back pain in the United States. Spine (Phila, Pa 1976) 2004;29(23):E531-7.

[5] Chou R, Peterson K, Helfand M. Comparative efficacy and safety of skeletal muscle relaxants for spasticity and musculoskeletal conditions: a systematic review. J Pain Symptom Manage 2004;28(2): $140-75$.

[6] van Tulder MW, Touray T, Furlan AD, et al. Muscle relaxants for nonspecific low back pain. Cochrane Database Syst Rev 2003(2): CD004252.
[7] Bronstein AC, Spyker DA, Cantilena Jr LR, et al. 2007 Annual Report of the American Association of Poison Control Centers' National Poison Data System (NPDS): 25th Annual Report. Clin Toxicol (Phila) 2008;46(10):927-1057.

[8] Mills KC. Tricyclic antidepressants. In: Tintinalli JE, Kelen GD, Stapczynski JS, editors. Emergency medicine: a comprehensive study guide. 6th ed. New York: McGraw-Hill, Medical Pub. Division; 2004. p. xxxix.2043

[9] Hessler RA. Cardiovascular principles. In: Goldfrank LR, Flomenbaum N, editors. Goldfrank's toxicologic emergencies. 8th ed. New York: McGraw-Hill, Medical Pub. Division; 2006. p. 364-79.

[10] Spiller HA, Winter ML, Mann KV, et al. Five-year multicenter retrospective review of cyclobenzaprine toxicity. J Emerg Med 1995;13(6):781-5

[11] Ruha AM, Curry SC, Riley B, Pizon A. Cyclobenzaprine and prolonged anticholinergic toxicity, hypotension, and mild intraventricular conduction delay. J Toxicol Clin Toxicol 2004;42(5):721.

[12] American Association of Poison Control Centers. National Poison Data System Reference Manual. Washington, DC: American Association of Poison Centers; 2007.

[13] Boehnert MT, Lovejoy Jr FH. Value of the QRS duration versus the serum drug level in predicting seizures and ventricular arrhythmias after an acute overdose of tricyclic antidepressants. N Engl J Med 1985;313(8):474-9.

[14] O'Riordan W, Gillette P, Calderon J, et al. Overdose of cyclobenzaprine, the tricyclic muscle relaxant. Ann Emerg Med 1986;15(5): 592-3.

[15] Linden CH, Mitchiner JC, Lindzon RD, et al. Cyclobenzaprine overdosage. J Toxicol Clin Toxicol 1983;20(3):281-8.

[16] Gilbert EH, Lowenstein SR, Koziol-McLain J, et al. Chart reviews in emergency medicine research: where are the methods? Ann Emerg Med 1996;27(3):305-8.

[17] Nibbelink DW, Strickland SC. Cyclobenzaprine (Flexeril) postmarketing surveillance program: preliminary report. Curr Ther Res 1979;25: $564-70$.

[18] Tokarski GF, Young MJ. Criteria for admitting patients with tricyclic antidepressant overdose. J Emerg Med 1988;6(2):121-4.

[19] Spiller HA, Cutino L. Fatal cyclobenzaprine overdose with postmortem values. J Forensic Sci 2003;48(4):883-4.

[20] Share NN, McFarlane CS. Cyclobenzaprine: novel centrally acting skeletal muscle relaxant. Neuropharmacology 1975;14(9):675-84.

[21] Hoffman RS. Understanding the limitations of retrospective analyses of poison center data. Clin Toxicol (Phila) 2007;45(8):943-5. 